\title{
Arresting chromosome replication upon energy starvation in Escherichia coli
}

\author{
Godefroid Charbon $^{1} \cdot$ Jakob Frimodt-Møller ${ }^{1} \cdot$ Anders Løbner-Olesen $^{1}$ (i)
}

Received: 14 June 2021 / Revised: 7 July 2021 / Accepted: 7 July 2021 / Published online: 3 August 2021

(c) The Author(s) 2021

\begin{abstract}
Most organisms possess several cell cycle checkpoints to preserve genome stability in periods of stress. Upon starvation, the absence of chromosomal duplication in the bacterium Escherichia coli is ensured by holding off commencement of replication. During normal growth, accumulation of the initiator protein DnaA along with cell cycle changes in its activity, ensure that DNA replication starts only once per cell cycle. Upon nutrient starvation, the prevailing model is that an arrest in DnaA protein synthesis is responsible for the absence of initiation. Recent indications now suggest that DnaA degradation may also play a role. Here we comment on the implications of this potential new layer of regulation.
\end{abstract}

Keywords Cellular Energy Status · Chromosome replication $\cdot$ DnaA $\cdot$ Genome stability

\section{Introduction}

Nutrient availability affects the cell cycle of all organisms. In Eukaryotes, checkpoints known as 'Restriction' or 'Start' prolong the G1 phase following nutritional stress until a favorable cellular energy state is reached (Johnson and Skotheim 2013; Solaki and Ewald 2018). In the well-studied prokaryotic organism Escherichia coli, no such checkpoints have been identified. Instead, accumulation of the initiator protein DnaA, whose expression is coupled to mass increase, is thought to play a determining role in deciding when DNA synthesis starts (Lobner-Olesen et al. 1989; Si et al. 2017).

\section{Initiation of DNA replication depends on accumulation and activation of DnaA}

DnaA is a multi-domain protein that binds the origin of replication and loads the replicative helicase (Hansen and Atlung 2018; Katayama et al. 2017; Leonard and Grimwade

\section{Communicated by Michael Polymenis.}

Godefroid Charbon

Godefroid.charbon@bio.ku.dk

$\triangle$ Anders Løbner-Olesen

lobner@bio.ku.dk

1 Department of Biology, University of Copenhagen, Ole Maløes Vej 5, 2200 Copenhagen N, Denmark
2015; Riber et al. 2016). Like other initiator proteins, it possess an AAA + domain with ATPase activity that determines its ability to form a nucleoprotein structure on the origin and to load the helicase; the initiator being active when bound to ATP while inactive in its ADP bound form. Because DnaA has an equally high affinity for ATP and ADP and because ATP is about seven times more abundant in the cell than ADP during normal growth, it is assumed that newly synthesized DnaA mainly binds ATP. In other words, the energy state of the cell could influence the ratio of active to inactive initiator. Thus it is expected that overproduction of DnaA will increase the amount of DnaA ${ }^{\text {ATP }}$ relative to $\mathrm{DnaA}^{\mathrm{ADP}}$. Accordingly, overproduction of a mutant DnaA that binds ATP and ADP equally well but has lost its ATPase activity (DnaAR334A), results in an increase of DnaA ${ }^{\text {ATP }}$ from $\sim 10 \%$ to $\sim 60 \%$ and an enormous increase in initiation frequency (Nishida et al. 2002). Contrary to the expectation, overproduction of wild-type DnaA does not increase or even reduce the ratio DnaA ${ }^{\mathrm{ATP}} / \mathrm{DnaA}^{\mathrm{ADP}}$ (Kurokawa et al. 1999; Nishida et al. 2002) and has a relatively minor effect on the initiation frequency (Nishida et al. 2002; Riber et al. 2006). The fact that an accumulation of DnaA ${ }^{\text {ATP }}$ alone is much more potent in starting DNA replication than an accumulation of DnaA ${ }^{\text {ATP }}$ together with DnaA ${ }^{\mathrm{ADP}}$ indicates that DnaA ${ }^{\mathrm{ADP}}$ has an inhibitory function on initiation. Thus, DnaA needs to be both in sufficient amount and predominantly in active form (high $\mathrm{DnaA}^{\mathrm{ATP}} / \mathrm{DnaA}^{\mathrm{ADP}}$ ratio) to start DNA replication (Fig. 1). DnaA is predominantly found in 


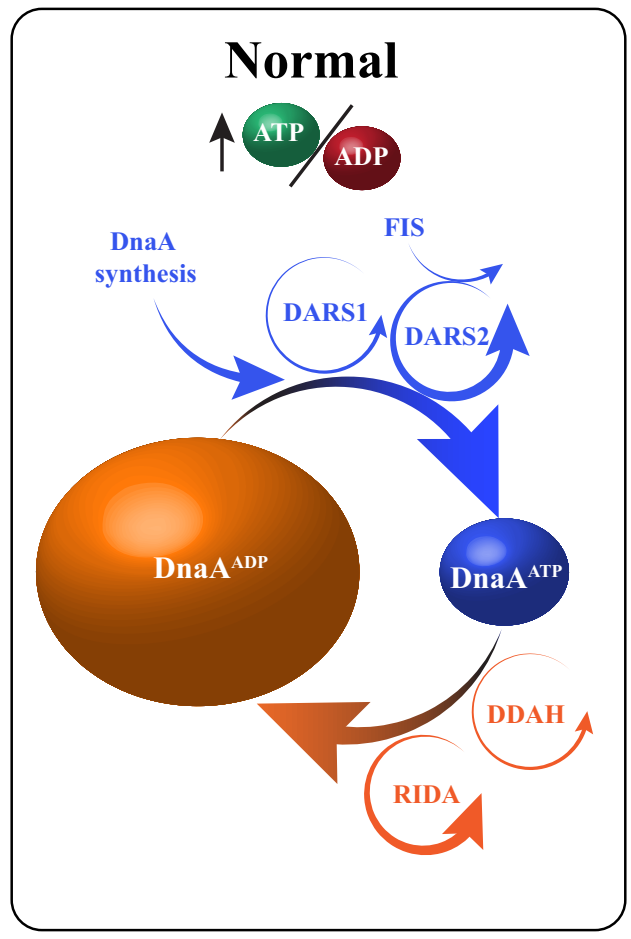

Fig. 1 Regulation of DnaA activity. During normal growth (left), DnaA $^{\text {ATP }}$ (blue) is formed through DnaA synthesis (apo-DnaA binding ATP that is more abundant than ADP) and by DARS 'rejuvenation' (DARS1 and FIS-dependent DARS2) through dissociation of $\mathrm{ADP}$ from DnaA ${ }^{\mathrm{ADP}}$ (orange). The formation of $\mathrm{DnaA}^{\mathrm{ADP}}$ is con-

the ADP bound form at the population level ( 70\%) (Kato and Katayama 2001). This is because the nucleotide bound state of DnaA is determined by a balance between control mechanisms.

\section{Regulation of DnaA activity}

On one hand, there is Regulatory Inactivation of DnaA (RIDA) (Kato and Katayama 2001) and datA-dependent DnaAATP hydrolysis (DDAH) (Kasho and Katayama 2013) that stimulate DnaA ATPase activity to reduce the $\mathrm{DnaA}^{\mathrm{ATP}} / \mathrm{DnaA}^{\mathrm{ADP}}$ ratio. On the other hand, the rejuvenation of DnaA ${ }^{\mathrm{ADP}}$ to DnaA ${ }^{\mathrm{ATP}}$ at DnaA Rejuvenating Sequences DARS1 and DARS2 serves to increase the $\mathrm{DnaA}^{\mathrm{ATP}} / \mathrm{DnaA}^{\mathrm{ADP}}$ ratio by promoting the dissociation of ADP from DnaA (Fujimitsu et al. 2009); the Apo-DnaA produced binds preferentially ATP (Fig. 1). These regulatory mechanisms act in concert during the cell cycle to ensure that DnaA ${ }^{\text {ATP }}$ accumulates pre-initiation and is subsequently converted to DnaA ${ }^{\mathrm{ADP}}$ post-initiation. Mechanistically, DDAH at the datA locus and rejuvenation at DARS sites distinguish themselves by the type of DnaA-DNA complex formed and the auxiliary proteins required to function. DARSI is constitutively active and

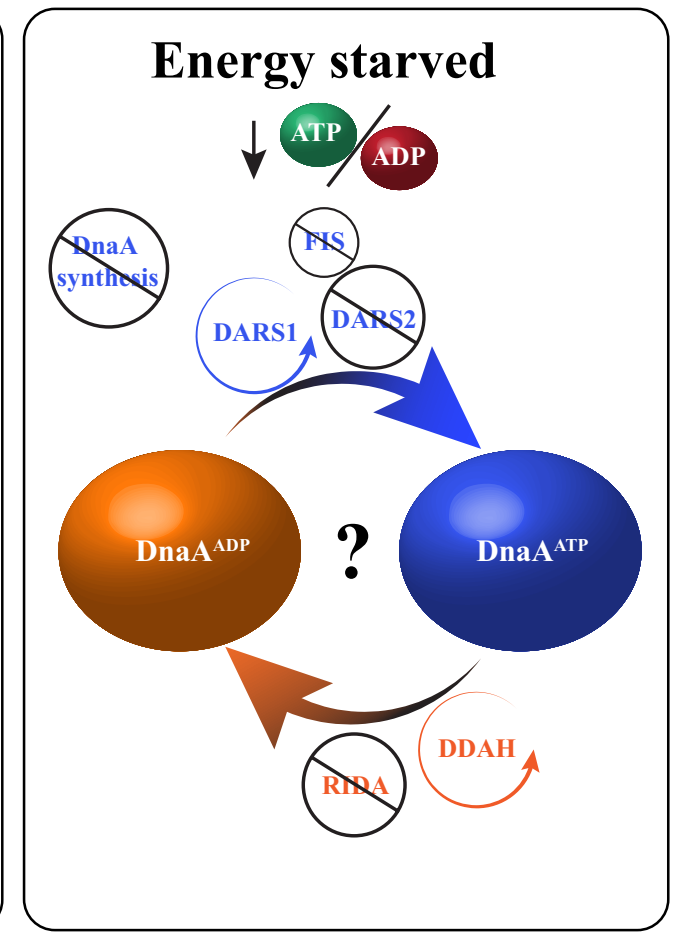

trolled by DDAH and RIDA through stimulaion of DnaA ATPase activity. On average, total DnaA is constituted of $30 \%$ DnaA $^{\text {ATP }}$ and $\sim 70 \% \mathrm{DnaA}^{\mathrm{ADP}}$ in exponentially growing cells. In energy starved cell (right), DARS2 and RIDA are both inactive, and the ratio $\mathrm{DnaA}^{\mathrm{ATP}} / \mathrm{DnaA}{ }^{\mathrm{ADP}}$ is not known

does not require helper proteins while IHF is required for DDAH and DARS2. Rejuvenation at DARS2 rejuvenation is also depends on Fis function and is expected to be growth phase regulated (Frimodt-Moller et al. 2016; Inoue et al. 2016; Kasho et al. 2014) because Fis is abundant in exponential phase but absent during stationary phase. RIDA, is orchestrated by the Hda protein interacting with the DNA loaded $\beta$-clamps. During replication, $\beta$-clamps tether the DNA polymerase to the template DNA. However, numerous $\beta$-clamps are left loaded on double stranded DNA behind the replication forks for several minutes (Moolman et al. 2014). These DNAbound $\beta$-clamps act as a platform for several activities such as DNA repair and in the case of RIDA serve to complex DnaA with the protein HdA resulting in activation of DnaA ATPase. RIDA is expected to be less active in absence of DNA replication where few $\beta$-clamps are left loaded on DNA (Katayama et al. 1998; Kurokawa et al. 1999). Because RIDA is the predominant process lowering the DnaA ${ }^{\mathrm{ATP}} / \mathrm{DnaA}^{\mathrm{ADP}}$ ratio, we speculate that DnaA becomes more ATP-bound during stationary phase and energy starvation (Fig. 1). In cells where only DDAH and DARS1 are functional, the $\mathrm{DnaA}^{\mathrm{ATP}} / \mathrm{DnaA}^{\mathrm{ADP}}$ ratio increases (Fujimitsu et al. 2009). Furthermore, DnaA ${ }^{\text {ADP }}$ 
is slowly converted into DnaA ${ }^{\mathrm{ATP}}$ in a RIDA-deficient cell when protein synthesis is blocked by chloramphenicol treatment (Fujimitsu et al. 2009; Kurokawa et al. 1999).

\section{DnaA synthesis arrest upon starvation}

Upon energy starvation, DNA replication stops and it was assumed that a general reduction in protein synthesis (Holm et al. 2010), including DnaA, is responsible for this arrest (Fig. 2). In this model, DnaA fails to accumulate to a level
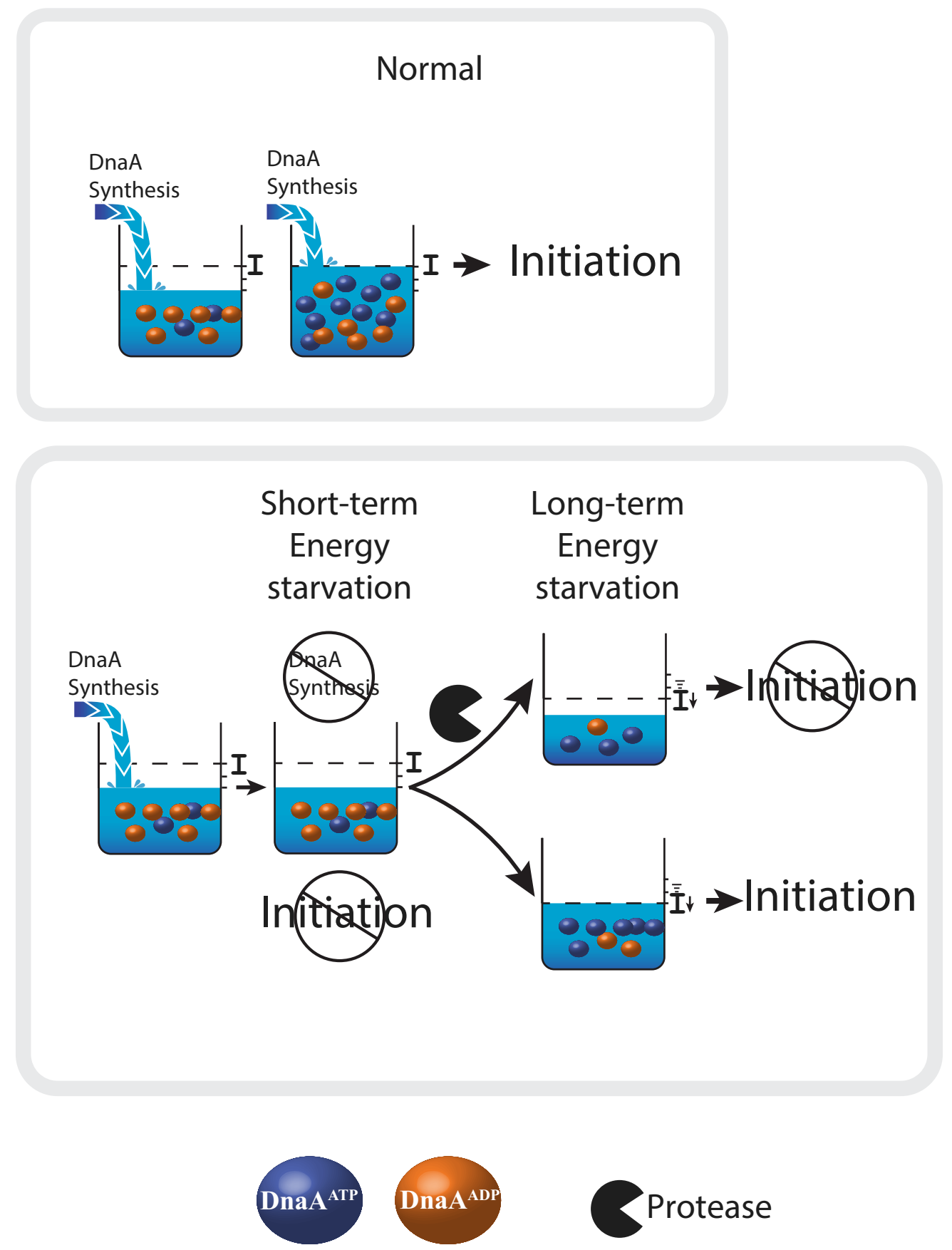

Fig. 2 A role for degradation of DnaA during energy etarvation. During normal growth (upper panel), DNA replication is initiated when enough DnaA molecules have accumulated and when DnaA ${ }^{\text {ATP/ }}$ $\mathrm{DnaA}^{\mathrm{ADP}}$ is high (level of DnaA required to for initiation: I). During short-term energy starvation (lower panel), DnaA does not accumu- late to sufficient level and DnaA ${ }^{\mathrm{ATP}} / \mathrm{DnaA}^{\mathrm{ADP}}$ is low. During longterm energy starvation, we propose that $\mathrm{DnaA}^{\mathrm{ATP}} / \mathrm{DnaA}^{\mathrm{ADP}}$ becomes sufficiently high to allow for replication initiation despite of fewer DnaA molecules, unless DnaA level is lowered by degradation 
sufficient to promote a new round of replication. The DNA replication arrest is specific to the initiation step, with ongoing replication allowed to proceed to completion. This is also the case when DnaA expression is blocked by treatment with antibiotics that arrest protein synthesis such as chloramphenicol and rifampicin or during the stringent response when the alarmone (p)ppGpp is induced (Chiaramello and Zyskind 1990; Lark 1972; Schreiber et al. 1995; Skarstad et al. 1986). This is corroborated by the fact that the hyperactive DnaA mutant DnaAcos continues to initiate DNA replication in the presence of chloramphenicol (Kellenberger-Gujer et al. 1978) and by the observation that overexpression of dnaA bypasses the DNA replication arrest seen in (p)ppGppinduced cells (Riber and Lobner-Olesen 2020).

\section{DnaA degradation during ATP starvation}

Recently, a manipulation of the cellular ATP level indicates that additional regulation mechanism exist. Normally, DnaA is extremely stable during steady state growth, with protein half-life exceeding $24 \mathrm{~h}$ (Atlung and Hansen 1999; Torheim et al. 2000). It is shown now that depletion of ATP results in a replication initiation arrest as expected, but surprisingly, this is accompanied by degradation of about $30 \%$ of the DnaA proteins after 1-hour ATP starvation (Charbon et al. 2021). The nucleotide binding of DnaA does not affect DnaA stability during energy starvation (Charbon et al. 2021). However, the mechanism responsible for the degradation remains elusive and neither of the ATP-dependent proteases Lon or ClpP, implicated in the initiator proteolysis in the bacterium Caulobacter crescentus, are involved. Following carbon starvation, a similar DNA synthesis arrest is observed despite the fact that DnaA is stable during the initial stages of starvation where ATP/ADP level is remains unchanged. Nonetheless, following long-term carbon starvation, the ATP/ADP level falls (Chapman et al. 1971), and DnaA is degraded (Charbon et al. 2021).

\section{DnaA degradation during stringent response}

Although DnaA was originally described as stable or even more abundant in stationary phase (Ali Azam et al. 1999; Sakakibara and Yuasa 1982; Sekimizu et al. 1988), recent work indicates that DnaA is degraded during the stringent response (increased levels of (p)ppGpp) occurring upon entry into stationary phase, or upon amino acid starvation (Gross and Konieczny 2020). Indeed, the amount of DnaA per cell decreases over time following induction of (p)ppGpp, a decrease that is not observed in a lon or $p p k$ mutant (polyphosphate synthesis). In vitro, Lon specifically degrades DnaA ${ }^{\mathrm{ADP}}$ in the presence of polyphosphate (PolyP) (Gross and Konieczny 2020). Thus it is proposed that accumulation of PolyP acts as a starvation signal to degrade DnaA and prevent initiation of DnaA replication. Note that the degradation of DnaA apparently depends on how (p)ppGpp is induced as it is not observed elsewhere (Riber and Lobner-Olesen 2020).

\section{A new regulatory mechanism?}

Because dnaA expression is reduced or arrested during energy starvation and the stringent response respectively, future work should address the need for DnaA degradation as extra layer of regulation. For example, for cells entering carbon starvation, the DNA replication block does not require DnaA degradation (Charbon et al. 2021). In this case, cessation of de novo DnaA synthesis is sufficient to arrest initiation and degradation of DnaA comes only much later. The question therefore remains why DnaA degradation in ATP depleted or (p)ppGpp accumulating cell is at all necessary. One possibility is that DnaA degradation is incidental; i.e., DnaA instability may be a mere consequence of a protein degradation in general. This explains why mutants in proteolytic pathways have not been isolated in genetic screens for suppression of DnaA hyperactivity (Charbon et al. 2018). On the other hand, although the block in expression of DnaA is a sufficient short-term solution, we suggest that it becomes ineffective if the $\mathrm{DnaA}^{\mathrm{ATP}} / \mathrm{DnaA}^{\mathrm{ADP}}$ balance increases over time (Fig. 2). We speculate that upon long-term energy starvation during which RIDA and DARS2 are inactive, DnaA ${ }^{\mathrm{ADP}}$ is converted into DnaA ${ }^{\mathrm{ATP}}$ overtime, thereby lowering the number of DnaA molecules needed to trigger initiation of replication (Fig. 2). Thus, DnaA is capable to re-initiate DNA replication despite being at a level normally deemed insufficient. This is in accordance with the observation that a hyperactive DnaA protein mimicking DnaA ${ }^{\text {ATP }}$ can continue to initiate new rounds of replication despite protein synthesis arrest (KellenbergerGujer et al. 1978). Degradation of DnaA in general during ATP depletion (Charbon et al. 2021) could lower the cellular amount of protein and prevent this (Fig. 2). The observation that specifically DnaA ${ }^{\mathrm{ADP}}$ is degraded during PolyP accumulation (Gross and Konieczny 2020) is counterintuitive, as this would increase the $\mathrm{DnaA}^{\mathrm{ATP}} / \mathrm{DnaA}^{\mathrm{ADP}}$ ratio and theoretically lower the amount of DnaA needed to start replication; fewer DnaA molecules but more active. Since DnaA ${ }^{\mathrm{ADP}}$ is the most abundant species, accounting for $70 \%$ of total DnaA, DnaA ${ }^{\text {ADP }}$ proteolysis could provide a fast way to degrade the majority of DnaA molecules. However this is not supported by the modest $\sim 20 \%$ reduction in total DnaA observed after 30-min amino acid starvation (Gross and Konieczny 2020). On the other hand, degrading the inactive form of DnaA could be a way to quickly restart DNA replication following starvation. Post starvation, cells would be left with only DnaA ${ }^{\text {ATP }}$ and therefore fewer DnaA molecules would be required to re-initiate. Finally, we do 
not exclude that the role of DnaA degradation is to control transcriptional activity (Messer and Weigel 1997) instead of or in addition to its initiator activity. Indeed, DnaA overproduction during late phase has been reported to induce the transcription of polA gene encoding DNA polymerase $\mathrm{I}$ in a manner independent of the late phase sigma factor RpoS (Quinones, et al. 1997). Thus, DnaA transcriptionial activity could clash with other master regulators specialized in promoting survival during starvation, justifying DnaA degradation.

\section{Authors' contributions GC, JFM and ALO drafted the manuscript.}

Funding This research was funded by grants from the Danish National Research Foundation (DNRF120), from the Novo Challenge Center for Peptide-Based Antibiotics NNF16OC0021700 (Cepan), and from the Villum Foundation through the Villum Experiment Programme, Grant no. 35894.

Data availability Not relevant.

Code availability Not relevant.

\section{Declarations}

Conflicts of interest There are no conflicts of interest.

Open Access This article is licensed under a Creative Commons Attribution 4.0 International License, which permits use, sharing, adaptation, distribution and reproduction in any medium or format, as long as you give appropriate credit to the original author(s) and the source, provide a link to the Creative Commons licence, and indicate if changes were made. The images or other third party material in this article are included in the article's Creative Commons licence, unless indicated otherwise in a credit line to the material. If material is not included in the article's Creative Commons licence and your intended use is not permitted by statutory regulation or exceeds the permitted use, you will need to obtain permission directly from the copyright holder. To view a copy of this licence, visit http://creativecommons.org/licenses/by/4.0/.

\section{References}

Ali Azam T et al (1999) Growth phase-dependent variation in protein composition of the Escherichia coli nucleoid. J Bacteriol 181(20):6361-6370

Atlung T, Hansen FG (1999) Low-temperature-induced DnaA protein synthesis does not change initiation mass in Escherichia coli K-12. J Bacteriol 181(18):5557-5562

Chapman AG, Fall L, Atkinson DE (1971) Adenylate energy charge in Escherichia coli during growth and starvation. J Bacteriol 108(3):1072-1086

Charbon $\mathrm{G}$ et al (2021) Energy starvation induces a cell cycle arrest in Escherichia coli by triggering degradation of the DnaA initiator protein. Front Mol Biosci 8:629953

Charbon G, Riber L, Lobner-Olesen A (2018) Countermeasures to survive excessive chromosome replication in Escherichia coli. Curr Genet 64(1):71-79
Chiaramello AE, Zyskind JW (1990) Coupling of DNA replication to growth rate in Escherichia coli: a possible role for guanosine tetraphosphate. J Bacteriol 172(4):2013-2019

Frimodt-Moller J et al (2016) DNA replication control is linked to genomic positioning of control regions in Escherichia coli. PLoS Genet 12(9):e1006286

Fujimitsu K, Senriuchi T, Katayama T (2009) Specific genomic sequences of E. coli promote replicational initiation by directly reactivating ADP-DnaA. Genes Dev 23(10):1221-1233

Gross MH, Konieczny I (2020) Polyphosphate induces the proteolysis of ADP-bound fraction of initiator to inhibit DNA replication initiation upon stress in Escherichia coli. Nucleic Acids Res 48(10):5457-5466

Hansen FG, Atlung T (2018) The DnaA tale. Front Microbiol 9:319

Holm AK et al (2010) Metabolic and transcriptional response to cofactor perturbations in Escherichia coli. J Biol Chem 285(23):17498-17506

Inoue $\mathrm{Y}$ et al (2016) Chromosomal location of the DnaA-reactivating sequence DARS2 is important to regulate timely initiation of DNA replication in Escherichia coli. Genes Cells 21(9):1015-1023

Johnson A, Skotheim JM (2013) Start and the restriction point. Curr Opin Cell Biol 25(6):717-723

Kasho K, Katayama T (2013) DnaA binding locus datA promotes DnaA-ATP hydrolysis to enable cell cycle-coordinated replication initiation. Proc Natl Acad Sci USA 110(3):936-941

Kasho K et al (2014) Timely binding of IHF and Fis to DARS2 regulates ATP-DnaA production and replication initiation. Nucleic Acids Res 42(21):13134-13149

Katayama T et al (1998) The initiator function of DnaA protein is negatively regulated by the sliding clamp of the E. coli chromosomal replicase. Cell 94(1):61-71

Katayama T, Kasho K, Kawakami H (2017) The DnaA cycle in escherichia coli: activation, function and inactivation of the initiator protein. Front Microbiol 8:2496

Kato J, Katayama T (2001) Hda, a novel DnaA-related protein, regulates the replication cycle in Escherichia coli. EMBO J 20(15):4253-4262

Kellenberger-Gujer G, Podhajska AJ, Caro L (1978) A cold sensitive dnaA mutant of E. coli which overinitiates chromosome replication at low temperature. Mol Gen Genet 162(1):9-16

Kurokawa K et al (1999) Replication cycle-coordinated change of the adenine nucleotide-bound forms of DnaA protein in Escherichia coli. EMBO J 18(23):6642-6652

Lark KG (1972) Evidence for the direct involvement of RNA in the initiation of DNA replication in Escherichia coli 15T. J Mol Biol 64(1):47-60

Leonard AC, Grimwade JE (2015) The orisome: structure and function. Front Microbiol 6:545

Lobner-Olesen A et al (1989) The DnaA protein determines the initiation mass of Escherichia coli K-12. Cell 57(5):881-889

Messer W, Weigel C (1997) DnaA initiator-also a transcription factor. Mol Microbiol 24(1):1-6

Moolman MC et al (2014) Slow unloading leads to DNA-bound beta2sliding clamp accumulation in live Escherichia coli cells. Nat Commun 5:5820

Nishida S et al (2002) A nucleotide switch in the Escherichia coli DnaA protein initiates chromosomal replication: evidnece from a mutant DnaA protein defective in regulatory ATP hydrolysis in vitro and in vivo. J Biol Chem 277(17):14986-14995

Quinones A et al (1997) DnaA protein stimulates polA gene expression in Escherichia coli. Mol Microbiol 23(6):1193-1202

Riber L, Lobner-Olesen A (2020) Inhibition of Escherichia coli chromosome replication by rifampicin treatment or during the stringent response is overcome by de novo DnaA protein synthesis. Mol Microbiol 114(6):906-919 
Riber L et al (2006) Hda-mediated inactivation of the DnaA protein and dnaA gene autoregulation act in concert to ensure homeostatic maintenance of the Escherichia coli chromosome. Genes Dev 20(15):2121-2134

Riber L et al (2016) Multiple DNA binding proteins contribute to timing of chromosome replication in E. coli. Front Mol Biosci 3:29

Sakakibara Y, Yuasa S (1982) Continuous synthesis of the dnaA gene product of Escherichia coli in the cell cycle. Mol Gen Genet 186(1):87-94

Schreiber G, Ron EZ, Glaser G (1995) ppGpp-mediated regulation of DNA replication and cell division in Escherichia coli. Curr Microbiol 30(1):27-32

Sekimizu K, Yung BY, Kornberg A (1988) The dnaA protein of Escherichia coli. Abundance, improved purification, and membrane binding. J Biol Chem 263(15):7136-7140
Si F et al (2017) Invariance of initiation mass and predictability of cell size in Escherichia coli. Curr Biol 27(9):1278-1287

Skarstad K, Boye E, Steen HB (1986) Timing of initiation of chromosome replication in individual Escherichia coli cells. EMBO J 5(7):1711-1717

Solaki M, Ewald JC (2018) Fueling the cycle: CDKs in carbon and energy metabolism. Front Cell Dev Biol 6:93

Torheim NK et al (2000) The Escherichia coli SeqA protein destabilizes mutant DnaA204 protein. Mol Microbiol 37(3):629-638

Publisher's Note Springer Nature remains neutral with regard to jurisdictional claims in published maps and institutional affiliations. 